\title{
Vascular Endothelial Growth Factor-Related Pathways in Hemato-Lymphoid Malignancies
}

\author{
Michael Medinger, ${ }^{1}$ Natalie Fischer, ${ }^{2}$ and Alexandar Tzankov ${ }^{3}$ \\ ${ }^{1}$ Department of Hematology, University Hospital Basel, Petersgraben 4, CH-4031 Basel, Switzerland \\ ${ }^{2}$ Clinic for Medical Oncology, University Hospital Basel, Petersgraben 4, CH-4031 Basel, Switzerland \\ ${ }^{3}$ Institute of Pathology, University Hospital Basel, Schoenbeinstrasse 40, CH-4031 Basel, Switzerland
}

Correspondence should be addressed to Alexandar Tzankov, atzankov@uhbs.ch

Received 6 November 2009; Revised 4 February 2010; Accepted 3 March 2010

Academic Editor: Arkadiusz Dudek

Copyright (C) 2010 Michael Medinger et al. This is an open access article distributed under the Creative Commons Attribution License, which permits unrestricted use, distribution, and reproduction in any medium, provided the original work is properly cited.

\begin{abstract}
Angiogenesis is essential for malignant tumor growth. This has been documented for solid tumors, and there is emerging evidence suggesting that tumor progression of hemato-lymphoid malignancies also depends on the induction of new blood vessel formation. The most important pro-angiogenic agent is vascular endothelial growth factor (VEGF), activating VEGF receptors 1 and 2. The available data on angiogenesis in hemato-lymphoid malignancies such as acute leukemias, myelodysplastic syndromes, myeloproliferative neoplasms, multiple myeloma and lymphomas, point towards the significance of autocrine and paracrine VEGF-mediated effects for proliferation and survival of leukemia/lymphoma cells in addition to tumor vascularization. Antiangiogenic strategies have become an important therapeutic modality for solid tumors. Several anti-angiogenic agents targeting VEGF-related pathways have are also being utilized in clinical trials for the treatment of hemato-lymphoid malignancies, and in some instances these pathways have emerged as promising therapeutic targets. This review summarizes recent advances in the basic understanding of the role of angiogenesis in hemato-lymphoid malignancies and the translation of such basic findings into clinical studies.
\end{abstract}

\section{Introduction}

New blood vessel formation (angiogenesis) is fundamental to tumor growth and spread. In adults, physiological angiogenesis is limited to a small number of specific processes, such as wound healing, tissue repair, and the female reproductive cycle [1]. The pioneering work of Judah Folkman led to the recognition that angiogenesis plays an important role in tumor development, progression, and metastasis [2]. Tumors require nutrients and oxygen to grow, and new blood vessels, formed by angiogenesis, provide these substrates. Tumor blood vessels are generated by various mechanisms, such as cooption of the existing vascular network, expansion of the host vascular network by budding of endothelial sprouts (sprouting angiogenesis), remodeling and expansion of vessels by the insertion of interstitial tissue columns into the lumen of preexisting vessels (intussusceptive angiogenesis), and homing of endothelial cell precursors (EPC;
CEP) from the bone marrow or peripheral blood into the endothelial lining of neovessels (vasculogenesis) [3]. Bone marrow-derived progenitor cells contribute significantly to neovascularization in a variety of tumors $[4,5]$.

The key mediator of angiogenesis is the vascular endothelial growth factor (VEGF). Its expression is regulated by a plethora of intrinsic and extrinsic factors, with hypoxia and hypoglycemia being the major stimuli [6]. Hypoxia-induced transcription of VEGF mRNA is mediated by binding of hypoxia-inducible factor 1 (HIF-1) [7]. Cytokines may also modulate angiogenesis by regulating VEGF expression, for example, tumor necrosis factor (TNF)- $\alpha$ increases VEGF mRNA in glioma cells [8], and transforming growth factor (TGF)- $\beta$ results in the induction of VEGF mRNA and protein in human lung adenocarcinoma cells [9]. In solid tumors, intratumoral hypoxia and HIF-1 mediation have been found to be a key angiogenesis triggering event [10]. Less is known about the exact trigger mechanisms of VEGF expression 


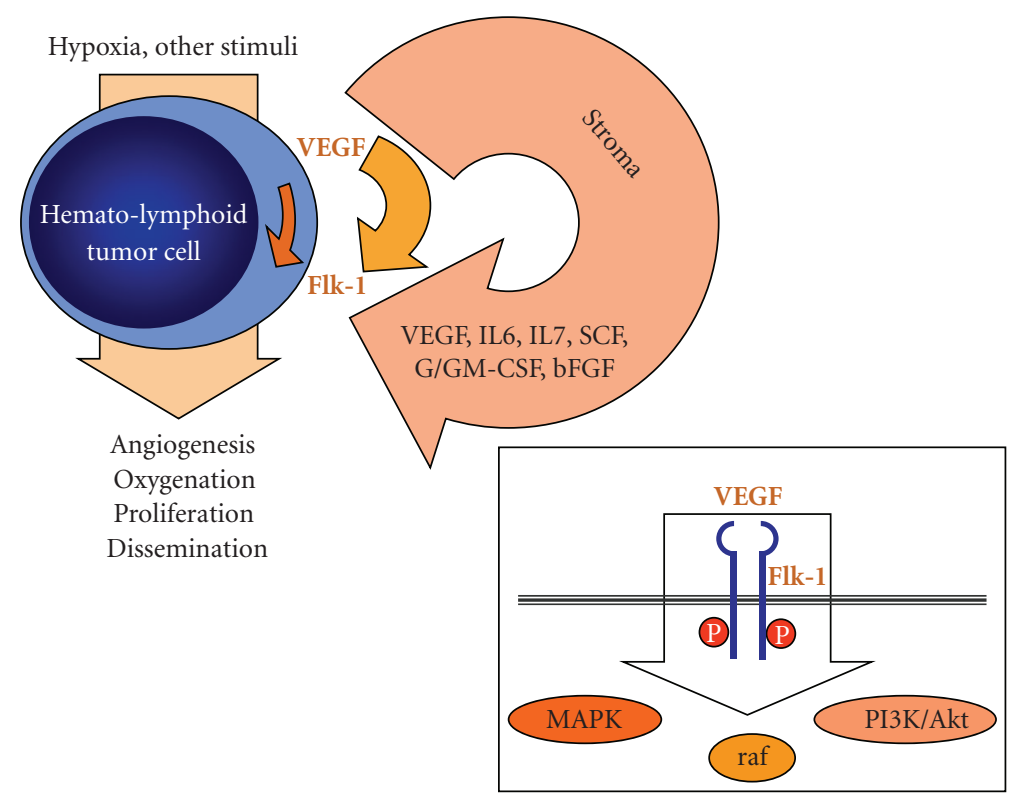

FIGURE 1: Possible vascular endothelial growth factor- (VEGF) and VEGF receptor-related (e.g., Flk-1, i.e., VEGFR-2) autocrine and paracrine loops in hemato-lymphoid neoplasms; insert: receptor tyrosine kinase activity and signaling cascades through VEGFR-2.

in hemato-lymphoid tumors, but mechanisms analogous to those observed in solid tumors are anticipated $[11,12]$. Tight control of angiogenesis is maintained by a balance of endogenous antiangiogenic and proangiogenic factors. VEGF has a key, rate-limiting role in promoting tumor angiogenesis and exerts its effects by binding to one of three tyrosine kinase receptors (Figure 1): VEGF receptor-1 (VEGFR-1; fms-like tyrosine kinase-1, Flt-1), VEGFR-2 (human kinase domain region, KDR/murine fetal liver kinase-1, Flk-1), and VEGFR-3 (Flt-4). VEGFR-1 (ligands include VEGF$\mathrm{A},-\mathrm{B}$, and placental growth factor [PIGF]) and VEGFR-2 (ligands include VEGF-A, -C, and -D) are predominantly expressed on vascular endothelial cells, and activation of VEGFR-2 appears to be both necessary and sufficient to mediate VEGF-dependent angiogenesis and induction of vascular permeability $[13,14]$. Both receptor tyrosine kinases are expressed in all adult endothelial cells except the brain. VEGFR-1 is also expressed on hematopoietic stem cells (HSC), vascular smooth muscle cells, monocytes, and leukemic cells $[15,16]$, while VEGFR-2 is expressed on endothelial progenitor cells and megakaryocytes [17, 18]. Although the exact contribution of VEGFR-1 signaling to angiogenesis is unclear, it has been shown that VEGFR-1 directly cooperates with VEGFR-2 via heterodimerization, as well as binding two additional VEGF homologues, VEGF$B$ and PIGF [19]. VEGFR-3, largely restricted to lymphatic endothelial cells, binds the VEGF homologues VEGF-C and VEGF-D and may play an important role in the regulation of lymphangiogenesis.

VEGF and VEGFR represent significant anticancer therapy targets that elegantly bypass potential tumor-related treatment barriers [13]. VEGF signaling inhibition has been shown to result in significant tumor growth delay in a wide range of animal models [20]. In the case of VEGF, even a single $V E G F$ allele knock-out led to embryonic lethality in mice [21]. The clinical benefit of this approach has also been confirmed, and concerted efforts in recent years have resulted in a number of novel antiangiogenic agents [22]. The first antiangiogenic agent to be approved was bevacizumab (Avastin, Genentech), a humanized anti-VEGF monoclonal antibody. Administration of bevacizumab, in combination with cytotoxic chemotherapy, conferred benefits to patients with metastatic colorectal cancer, nonsquamous, nonsmall cell lung cancer, and metastatic breast cancer [23-25], and it is now under investigation for patients with relapsed and refractory acute leukemia in combination with standard chemotherapy [26]. Additionally, two small-molecule inhibitors targeting VEGFR and other kinases, sorafenib (Nexavar, Bayer and Onyx pharmaceuticals) and sunitinib (Sutent, Pfizer), have been approved based on their efficacy in treating renal cell- and hepatocellular carcinoma $[27,28]$. A growing number of antiangiogenics are now either in various stages of clinical development or in clinical use as components of standard regimens (Table 1). The major classes of antiangiogenic therapy include (1) direct anti-VEGF acting molecules (anti-VEGF antibodies, VEGF-antisense nucleotides), (2) immunomodulatory drugs (IMIDs) with antiangiogenic properties, (3) receptor tyrosine kinase inhibitors that target VEGFR signaling as well as receptors of other (proangiogenic) factors, (4) the antiendothelial approach of metronomic therapy, and (5) other new compounds targeting signaling downstream to proangiogenic growth factors, such as mammalian target of rapamycin (mTOR) inhibitors, histone deacetylases' (HDAC) inhibitors, and proteasome inhibitors.

Several studies suggested that angiogenesis plays an important role, as might autocrine and paracrine VEGF/ VEGFR-related loops in hemato-lymphoid malignancies 
TABLE 1: Summary of clinical trials and approved antiangiogenic therapies in hemato-lymphoid malignancies.

\begin{tabular}{lccc}
\hline Drug class & Target & Study entities & Approved for \\
\hline $\begin{array}{l}\text { Anti-VEGF strategies } \\
\text { Bevacizumab (Avastin) }\end{array}$ & VEGF-A & AML, MDS, CLL, CML, NHL, & MM \\
\hline RTK inhibitors & $\begin{array}{c}\text { Metastatic colorectal cancer, } \\
\text { NSCLC, breast cancer }\end{array}$ \\
Vatalanib & VEGFR1-3, PDGFR $\beta$, CD117 & AML, PMF, MDS, CML, DLBCL, & \\
Cediranib (Recentin) & VEGFR1-3, PDGFR $\beta$, CD117 & AML, MDS, CLL & \\
\hline $\begin{array}{l}\text { Immunomodulators } \\
\text { Thalidomide }\end{array}$ & AML, MDS, MPN, CLL, NHL, & MM \\
Lenalidomide (Revlimid) & AML, MDS, CLL, NHL & MM, 5q-MDS \\
\hline
\end{tabular}

such as acute and chronic leukemias, myelodysplastic syndromes (MDS), myeloproliferative neoplasms (MPN), lymphomas, and multiple myeloma (MM) [29-39] (Figure 1). Moreover, angiogenesis appears to be targeted even by conventional chemotherapy in hemato-lymphoid malignancies; for example, patients with acute myelogenous leukemia (AML) show increased microvessel density (MVD) in the bone marrow with subsequent MVD reduction under chemotherapy and return to normal levels in cases of complete remission (CR) [31]. This review will focus on the current knowledge of angiogenesis and antiangiogenic therapies (related to classes 1 to 3 of antiangiogenic treatment approaches) in hemato-lymphoid malignancies.

\section{Acute Leukemias}

Leukemias have been ever since associated with angiogenesis since the AML cell line HL-60 was first used to clone the VEGF gene [40]. The first demonstration that leukemia progression might be accompanied by an increase of bone marrow vascularization was provided by Judah Folkman's group [41], who demonstrated that the bone marrow of acute lymphoblastic leukemia (ALL) patients had increased blood vessel content compared to normal counterparts. Detailed analysis of bone marrow sections from ALL patients led to the development of a model to illustrate their irregular, albeit abundant, bone marrow vasculature. Moreover, it was also shown that urine and peripheral blood samples from ALL patients contained elevated levels of proangiogenic growth factors, namely, basic fibroblast growth factor (bFGF) and VEGF, which correlated with the increase of bone marrow angiogenesis [41, 42]. These studies raised the question of whether the growth of other types of hematolymphoid malignancies is also accompanied by increased angiogenesis, while proving that the basic molecular/cellular mechanisms occurring during leukemia expansion might be similar to those seen in solid tumors. The existence of an "angiogenesis switch", first proposed for solid tumors [43], was therefore suggested to apply to hemato-lymphoid malignancies as well. "Angiogenesis switch" in leukemia is documented by increased bone marrow MVD (Figures 2(a) and 2(b)), increased expression of HIF-1, multiple proangiogenic factors (VEGF, bFGF, angiopoietin-2), soluble VEGFR, and decreased expression of endogenous angiogenesis inhibitors, such as thrombospondin-1 [11,12].

In a recent study by Norén-Nyström et al. [44], MVD, analyzed on 185 bone marrow biopsies, was higher in TALL compared to B-ALL. In the B-ALL group, cases with $t(12 ; 21)$ were characterized by a low MVD, while patients with hyperdiploid leukemia showed a high MVD. There was a correlation between MVD and white blood cell count in high-risk B-ALL patients. In addition, patients with a high marrow reticulin fiber density and high MVD had an unfavorable outcome. Similarly, in previously untreated AML, increased levels of plasma VEGF correlated with reduced survival and lower remission rates [45]. Moreover, the level of plasma/serum VEGF correlated with the number of circulating blasts [46], indicating the probable cellular origin of this proangiogenic factor. Such in vivo clinical studies are further supported by in vitro demonstrations of the capacity of leukemia cells to produce proangiogenic growth factors such as VEGF and bFGF [47-49]. Importantly, leukemia cells release increased amounts of proangiogenic factors in response to proinflammatory molecules, suggesting interactions with other cell types (e.g., the bone marrow stroma). In contrast to the abundant literature demonstrating that acute leukemia cells secrete significant amounts of angiogenesis activators such as VEGF, fewer studies have addressed the possibility that reduced production of angiogenesis inhibitors by these cells might also trigger the neovascularization process by shifting the local (bone marrow) angiogenesis balance $[50,51]$. In addition to the modulation of bone marrow angiogenesis by leukemia cells, it was demonstrated that subsets of cases express endothelialspecific tyrosine kinase receptors, such as VEGFR-1, -2, and -3 , or members of the FGF receptor family $[49,52$, 53]. Recent studies showed that even hematopoietic stem cells (HSC) express VEGFR and are capable of generating functional autocrine loops that support their proliferation and survival [54], raising the question of whether this might be of relevance for leukemic stem cells. 


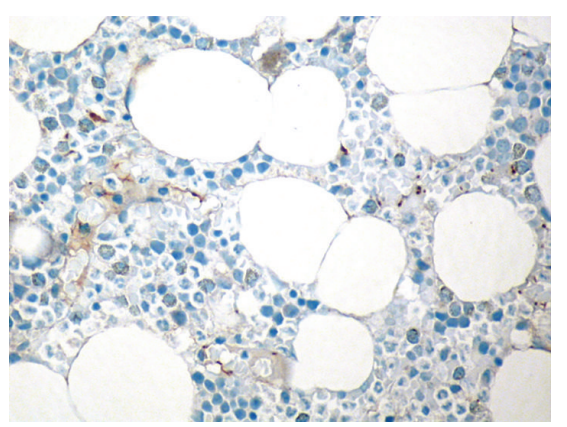

(a)

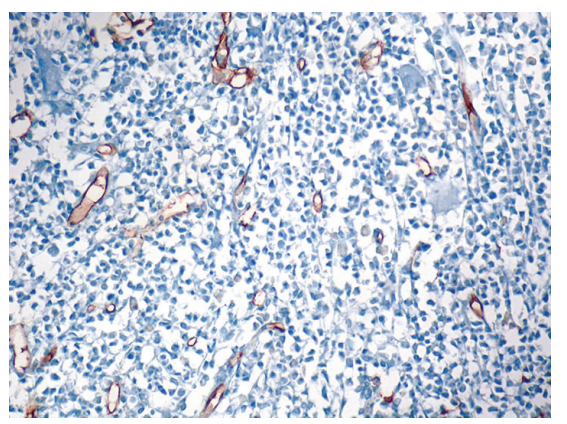

(b)

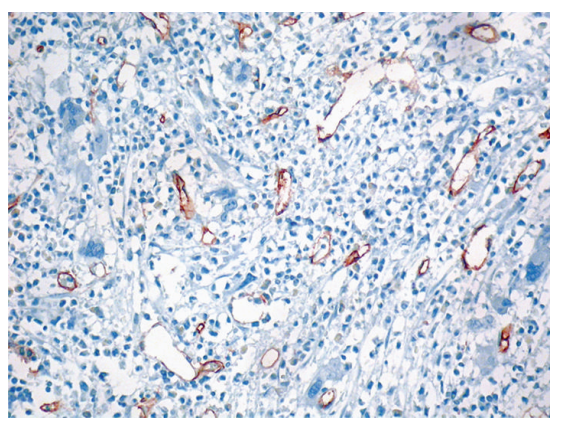

(c)

Figure 2: (a) Microvascular architecture in normal bone marrow highlighted by CD34; note single capillaries. (b) Increased microvessel density in acute myelogenous leukemia and in (c) myeloproliferative neoplasm; note dilated sinus and atypical megakaryocytes in the latter.

2.1. Antiangiogenic Therapy in Acute Leukemias. Bevacizumab is a humanized murine antihuman VEGF monoclonal $\operatorname{IgG}_{1}$ antibody that blocks the binding of human VEGF to its receptors, thereby also disrupting autocrine and paracrine survival mechanisms mediated by VEGFR-1 and VEGFR-2 [55]. In a Phase II clinical trial by Karp et al., bevacizumab was administered after chemotherapy to adults with refractory or relapsed AML [26]. Bevacizumab $10 \mathrm{mg} / \mathrm{kg}$ was administered on day 8 after cytarabine beginning day 1 and mitoxantrone beginning day 4. Forty-eight adults received induction therapy and the overall response was 23 of $48(48 \%)$, with CR in $16(33 \%)$. Eighteen patients (14 $\mathrm{CR}$ and 4 partial responses) underwent one consolidation cycle and 5 (3 CR and 2 partial responses) underwent allogeneic transplant. Median overall and disease-free survivals for CR patients were 16.2 months $(64 \%, 1$ year) and 7 months (35\%, 1 year), respectively. Bone marrow samples demonstrated marked MVD decrease after bevacizumab administration. VEGF was detected in pretreatment serum in $67 \%$ of patients tested, increased by day 8 to $52 \%$, and decreased to $93 \%$ (67\% undetectable) 2 hours after bevacizumab administration. Currently, bevacizumab is being evaluated as treatment option for newly diagnosed AML in combination with cytarabine and idarubicin in a phase II study.

Thalidomide, originally marketed as a sedative and antiemetic drug, was withdrawn from use subsequent to reports of teratogenicity in the 1960s. The initial use of thalidomide was the treatment of erythema nodosum leprosum. It has been shown that thalidomide has important immunomodulatory effects in that it decreases TNF- $\alpha$ synthesis and selectively modulates $\mathrm{T}$-cell subsets, shifting the T-cell population towards $\mathrm{T}$ helpers [56]. The interest in thalidomide as an antineoplastic agent rose after demonstration of its antiangiogenic activity in a rabbit model of corneal neovascularization that was induced in response to bFGF [57]. This report led to thalidomide application in MM, where it demonstrated a clinical benefit. Thalidomide and the newer IMIDs (e.g., lenalidomide) have been shown to significantly decrease the expression of the proangiogenic factors VEGF and interleukin-6 (IL-6) in MM [58]. The newer IMIDs were found to have 2-3 times more potent antiangiogenic activity than thalidomide in various in vivo assays [59]. The antiangiogenic activity of IMIDs has been shown to be independent of their immunomodulatory effects [60]. In AML patients, thalidomide therapy was assessed alone and in combination with other compounds. In a phase II study by Thomas et al. [61], thalidomide was analyzed in patients with relapsed or refractory AML previously treated with cytarabine-containing regimens. A total of 16 patients were treated with $200-800 \mathrm{mg} / \mathrm{d}$ oral thalidomide. Overall, one patient (6\%) achieved CR lasting for 36 months, and two patients had a transient reduction in marrow blasts from $8 \%$ and $7 \%$ to less than $5 \%$. There was no correlation between reduction of angiogenesis marker levels and response. In a phase I/II trial by Steins et al. [62], a dose-escalating trial was performed to study the safety and efficacy of thalidomide in 20 AML patients. Thirteen patients were assessable for both toxicity and response, tolerating a maximum dose of $200-400 \mathrm{mg} / \mathrm{d}$ for at least 1 month. Overall, adverse events were fatigue, constipation, rash, and neuropathy (grades 1 to 2 in most patients). In 4 patients, a partial response, defined as reduction of at least $50 \%$ of the blast cell infiltration in the bone marrow accompanied by increases of platelet counts and hemoglobin values, was observed. In parallel, MVD significantly decreased in these 5 patients during treatment with thalidomide. In a study by Barr et al. [63], thalidomide was examined in combination with fludarabine, carboplatin, and topotecan in 42 patients with poor prognosis AML, and 10 of 42 (24\%) patients achieved a CR. Serious thrombotic adverse events were observed in 5 patients, suggesting that the combination of cytotoxic chemotherapy and thalidomide may be thrombogenic despite significant thrombocytopenia. 
VEGF levels did not correlate with response to therapy, while a trend towards decreased MVD was noted in patients who achieved CR.

Small tyrosine kinase inhibitors that target VEGFR are a further important class of antiangiogenic drugs with application to AML, although their efficacy in hematolymphoid neoplasias, especially AML, might be attributable to inhibition of a variety of pathways, particularly those related to c-kit and flt3.

Vatalanib (formerly PTK787/ZK 222584) is an oral angiogenesis inhibitor that is active against VEGFR and PDGFR tyrosine kinases, thereby offering a novel approach to inhibiting tumor growth [64] by interfering with the ATP binding sites of VEGFR. In our phase I study, vatalanib was well tolerated and showed clinical activity in a variety of solid tumors [65]. In MM, its action primarily reduces the number of tumor microvessels and dilates the remaining vessels $[66,67]$. Ongoing studies are now evaluating the efficacy of vatalanib in combination with imatinib in a phase I/II trial for patients with AML, PMF, and blast phase of chronic myelogenous leukemia. Vatalanib was studied in a phase I clinical trial alone or in combination with cytosinearabinoside and daunorubicin in patients with MDS and AML [68]. Sixty-three patients received vatalanib at doses of $500-1000 \mathrm{mg} / \mathrm{bid}$ orally. At $1000 \mathrm{mg} / \mathrm{bid}$, dose-limiting toxicities resulting in lethargy, hypertension, nausea, emesis, and anorexia were observed. CR was observed in 5 of 17 evaluable AML patients treated with vatalanib combined with chemotherapy. The authors concluded that vatalanib is generally well tolerated and can be given in combination with chemotherapy in patients with MDS and AML. In a recent study by Barbarroja et al. [69], vatalanib was examined in combination with idarubicin in 4 AML cell lines and 7 AML patient samples. Vatalanib decreased VEGF levels and VEGFR phosphorylation in AML cells, which showed FLT3 internal tandem reduplications/mutations (ITD), raising questions about the actual targeted tyrosine kinase (VEGFR of flt3).

Cediranib (AZD2171, Recentin) is a potent inhibitor of both VEGFR-1 and VEGFR-2; it also has activity against ckit, PDGFR- $\beta$, and VEGFR-3 at nanomolar concentrations [70]. In our study, cediranib was well tolerated up to $45 \mathrm{mg} / \mathrm{d}$ in patients with a broad range of solid tumors [71], with the most common adverse side-effects being diarrhea, dysphonia, and hypertension. In a phase I study with cediranib in 35 AML patients, the most common adverse events were diarrhea, hypertension, and fatigue. Six patients experienced an objective response ( 3 each at 20 and $30 \mathrm{mg}$ ). Dose- and time-dependent reductions of soluble VEGFR-2 were observed, and there was a correlation between cediranib exposure and plasma VEGF levels [72].

\section{Myelodysplastic Syndromes}

In MDS, VEGF is overexpressed by immature myeloid cells in the bone marrow and associated with increased bone marrow vascularity [52]. MVD parallels disease progression from refractory anemia to secondary AML [32]. MDS patients also have increased proangiogenic factors in peripheral blood [73]. Higher levels of VEGF were found by immunohistochemistry and corroborated by reverse transcriptasepolymerase chain reaction in patients with refractory anemia with excess blasts (RAEB) and RAEB in transformation (RAEB-T), compared to patients with refractory anemia (RA) and with ringed sideroblasts (RARS) or normal bone marrow controls [74]. These differences were thought to result from expression of VEGF in immature myeloid cells in RAEB and RAEB-T. To evaluate the interplay between angiogenesis and cytokines, we conducted a study of 89 MDS cases and showed [34] that TNF- $\alpha$ expression and bone marrow MVD correlated with each other as well. Importantly, thalidomide, a drug that modulates T-cell function and inhibits TNF- $\alpha$ activity as well as angiogenesis, is under investigation in clinical trials for the treatment of MDS $[29,75]$.

3.1. Antiangiogenic Therapy in Myelodysplastic Syndromes. A combination therapy of thalidomide and 5-azacytidine, a hypomethylating drug, was assessed in 40 patients with MDS and AML [76]. Hematological improvement was observed in 15 of 36 patients (42\%), stable disease was observed in 5 of 36 patients (14\%), 10 of 36 patients (28\%) had disease progression, and six had CR. Lenalidomide, a synthetic compound derived by modifying the chemical structure of thalidomide, has also shown immunomodulatory and antiangiogenic properties and lower adverse effects rates [77]. Lenalidomide was investigated in a study of 148 MDS patients with $5 \mathrm{q}$ deletion [78]; 112 patients $(76 \%)$ had a reduced need for transfusions, and 99 (67\%) eliminated the need entirely regardless of karyotype complexity. Among 85 evaluable patients, 62 showed cytogenetic improvement, and 38 of that 62 showed complete cytogenetic remission. Therefore, lenalidomide was approved as a monotherapy for the treatment of transfusion-dependent MDS patients with $5 \mathrm{q}$ deletion with or without additional cytogenetic abnormalities.

\section{Multiple Myeloma}

MM is characterized by proliferation of malignant plasma cells that accumulate in the bone marrow and often produce a monoclonal immunoglobulin. MM was the first hematolymphoid malignancy in which increased angiogenesis was detected $[36,79]$. New vessel formation in the bone marrow seems to play an important role in the pathogenesis of MM [80, 81]. Increased bone marrow MVD in patients with $\mathrm{MM}$ also appears to be an important prognostic factor [82]. Malignant plasma cells can secrete various cytokines, including VEGF, bFGF, and hepatocyte growth factor (HGF), all known for their proangiogenic activity [83]. It has been shown that MM cells are capable of secreting VEGF in response to IL-6 stimulation, and in response to this VEGF stimulation, microvascular endothelial cells and bone marrow stromal cells in turn secrete IL-6, a potent growth factor for malignant plasma cells, thus closing a paracrine loop [84, 85]. Rajkumar et al. showed a gradual increase of bone marrow angiogenesis along the disease 
spectrum from monoclonal gammopathy of undetermined significance (MGUS) to smoldering MM, newly diagnosed MM, and relapsed MM [86], though the expression levels of VEGF, bFGF, and their receptors were similar among MGUS, smoldering MM, and newly diagnosed MM [87], suggesting that MVD increase in plasma cell neoplasias could be a function of chronology. In a recent study, Pour et al. examined $96 \mathrm{MM}$ patients at diagnosis and after high-dose chemotherapy with regard to angiogenesis factor/inhibitor concentrations in the peripheral blood and bone marrow plasma [88]. Based on a significant decrease of VEGF and hepatocyte growth factor levels, and a significant increase in TSP-1 thrombospondin-1 concentrations in the bone marrow plasma of patients who achieved complete or very good partial response versus those who had partial or no response, they concluded that a reduction in the rate of angiogenesis had occurred.

4.1. Antiangiogenic Therapy in Multiple Myeloma. Thalidomide monotherapy in a phase II trial of 84 patients with relapsed and refractory $\mathrm{MM}$ who had received doses ranging from 200 to $800 \mathrm{mg} / \mathrm{d}$ resulted in an overall response rate of $32 \%$. The 2-year event-free and overall survival were 20 and $48 \%$, respectively [89, 90]. In combination with dexamethasone, the response rate was $63 \%$ compared to $41 \%$ with dexamethasone alone in patients with newly diagnosed MM [91]. Subsequent to these studies, thalidomide was approved for the treatment of newly diagnosed MM. In 2 phase III trials, lenalidomide in combination with dexamethasone resulted in remarkable response rates and significantly less toxicity than thalidomide [92, 93], and increased the response rate from $22.5 \%$ to $59.2 \%$ compared to dexamethasone alone in patients with previously-treated relapsed/refractory MM. Lenalidomide was approved in combination with dexamethasone for second-line treatment of MM.

\section{Myeloproliferative Neoplasms}

The available data on angiogenesis and expression of VEGF and VEGFR in the bone marrow of patients with $B C R$ $A B L 1$-negative MPN suggest a significant increase of MVD (Figure 2(c)), especially in primary myelofibrosis (PMF), which might inversely correlate with survival [30, 33, 9497]. The identification of an acquired somatic mutation in the JAK2 gene, resulting in a valine to phenylalanine substitution at position 617 (JAK2-V617F), has provided new insights into the pathogenesis of $B C R-A B L 1$-negative MPN, which is found in most patients with polycythemia vera (PV) and in about $50 \%$ of patients with essential thrombocythemia (ET) and PMF [98, 99]. The correlations between angiogenesis and JAK2 status in MPN have been addressed in two studies with contradictory results [100, 101]. In a recent study [30], we found a significantly increased MVD and VEGF expression in MPN compared to controls, particularly in cases with high JAK2-V617F mutant allele burdens. Our results imply that higher activity of Jak2related pathways, as observed in cases with higher JAK2-
V617F mutant allele burdens, may influence angiogenesis in MPN. This assumption is further supported by our observation that the number of VEGF expressing cells did not rise concurrent with the increasing JAK2-V617F mutant allele burden regardless of rising MVD. Further support is provided by the study of $\mathrm{Zhu}$ et al. showing that $\mathrm{H}-2 \mathrm{~g}$, a glucose analog of the blood group $\mathrm{H}$ antigen, mediates endothelial cell chemotaxis and induces expression of the proangiogenic factors VEGF and bFGF through pathways involving Jak2 and phosphoinositide- 3 kinase that could be abolished by treatment with the respective inhibitors AG490 and LY294002 [102]. The importance of VEGF/Jak2/STAT5 pathways in angiogenesis is substantiated by evidence from another study as well suggesting tight interactions between VEGF and Jak2 [103]. Thus, it could be speculated that in at least some hemato-lymphoid neoplasms, such as BCR$A B L 1$-negative MPN, key tumor-related gate-keeping genetic mechanisms might also directly influence angiogenesis. A very recent study identified the JAK2-V617F mutation in microdissected endothelial cells form the liver veins of BuddChiari syndrome patients [104], raising the hypothesis that endothelial cells in PV are direct players in the neoplastic process.

5.1. Antiangiogenic Therapy in Myeloproliferative Neoplasms. In a phase II study of 44 PMF patients, the efficacy of thalidomide monotherapy was assessed [105]. Seventeen of 41 evaluable patients $(41 \%)$ receiving treatment for at least 15 days showed a response. CR (without reversal of bone marrow fibrosis) was achieved in 4 patients (10\%), partial response in 4 patients (10\%), and hematological improvements of anemia, thrombopenia, and/or splenomegaly were observed in 9 patients $(21 \%)$. A further phase II thalidomide and placebo study assessed the efficacy of thalidomide in the treatment of anemia in PMF [106]. The primary outcome was a $2 \mathrm{~g} / \mathrm{l}$ increase of hemoglobin levels resulting in a $20 \%$ reduction of transfusion needs. At 180 days, in an intention-to-treat analysis, no difference was observed between the thalidomide and placebo groups with regard to hemoglobin levels. In phase II studies with lenalidomide monotherapy in patients with symptomatic PMF, the overall response rates were 22\% for anemia, 33\% for splenomegaly, and 50\% for thrombocytopenia [107]. In a combination study of lenalidomide with prednisone in $40 \mathrm{PMF}$ patients [108], responses were recorded in 12 patients (30\%) and are ongoing in $10(25 \%)$, with a median time to response of 12 weeks. Three patients $(7.5 \%)$ had partial response and nine $(22.5 \%)$ had clinical improvement lasting a median of 18 months. Overall response rates were $30 \%$ for anemia and $42 \%$ for splenomegaly. Interestingly, all eight $J A K 2-V 617 F$-positive responders also experienced a reduction of the baseline mutant allele burden.

In another study, vatalanib was administered to $29 \mathrm{PMF}$ patients at doses of 500 or $750 \mathrm{mg} /$ bid. One patient $(3 \%)$ achieved CR and 5 (17\%) achieved clinical improvement. Cumulatively, these studies indicated that vatalanib had modest activity in PMF patients [109]. 


\section{Lymphomas}

MVD is significantly higher in nodal lymphomas, particularly in those that are highly proliferative, than in reactive lymph nodes (Figures 3(a) and 3(b)) [35, 110-113]. In extranodal lymphomas, for example, cutaneous T-cell and B-cell lymphomas, MVD are higher than in normal skin or benign cutaneous lymphoproliferative disorders [114116]. The interplay between lymphoma cells and tumor vessels is complex [117]; lymphoma-specific chromosomal aberrations such as $\mathrm{t}(8 ; 14), \mathrm{t}(11 ; 14)$, and $\mathrm{t}(14 ; 18)$ were discovered in tumor endothelial cells, calling into question the histogenesis of B-cell lymphoma vasculature [118]. Lymphoma growth and progression appear to be promoted by at least two distinct angiogenic mechanisms: autocrine stimulation of tumor cells via expression of VEGF and VEGFR by lymphoma cells, and paracrine influences of the proangiogenic tumor microenvironment on both local neovascular transformation and recruitment of circulating bone marrow-derived EPC [119]. The lymphoma microenvironment has been increasingly recognized as influencing neoplastic progression, in part by modulating angiogenic responses to distinct proangiogenic growth factors and cytokine milieu. In follicular lymphoma and diffuse large B-cell lymphoma (DLBCL), largescale gene expression profiling studies demonstrated that genetic signatures expressed by stromal and infiltrating immune cells defined distinct prognostic groups [120, 121]. In the study of Lenz et al. [121], DLBCL geneexpression signatures correlated with survival. A multivariate model, created from three gene-expression signatures termed "germinal-center B-cell", "stromal-1", and "stromal-2", predicted survival and was influenced by differences in immune cells, fibrosis, and particularly angiogenesis in the tumor microenvironment.

The prognostic and predictive value (as possible treatment target) of MVD and angiogenic factors in lymphomas is still controversial due to the heterogeneity of diseases, different classifications, and methods for analysis (immunohistochemistry, serum levels of angiogenic markers, mRNA extraction, etc.). In B-cell lymphomas, VEGF protein and mRNA have been identified in DLBCL, mantle cell lymphoma (MCL), central nervous system DLBCL, and viralrelated lymphomas [122]. A large study of 200 patients showed that high pretreatment levels of both serum VEGF and bFGF were independent prognostic factors for survival in multivariate analysis [123]. In a study with de novo DLBCL treated with anthracycline-based therapy, increased tumor vascularity was associated with poor overall survival independent of the international prognostic index [124]. Our results on the in situ expression of VEGF in B-cell lymphomas did not suggest a prognostic value, but showed distinct expression patterns among the different entities with higher prevalence in DLBCL [35]. Since VEGF expression in lymphomas parallels their proliferative activity [110-112], our findings of strong VEGF expression (20 out of 109 cases, $18 \%$ ) and highest MVD in DLBCL were not surprising (Figure 2(b)) [35]. We found no direct correlation between increased MVD and VEGF expression in DLBCL.

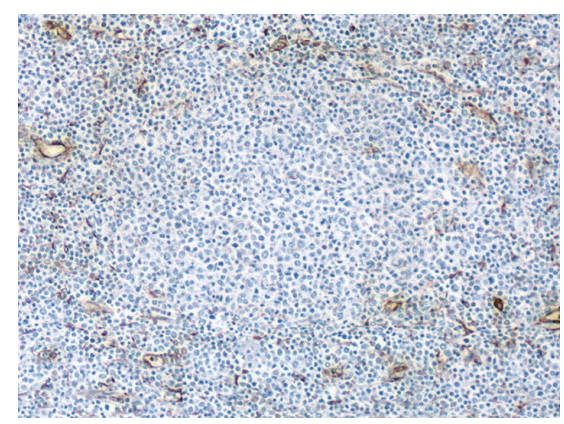

(a)

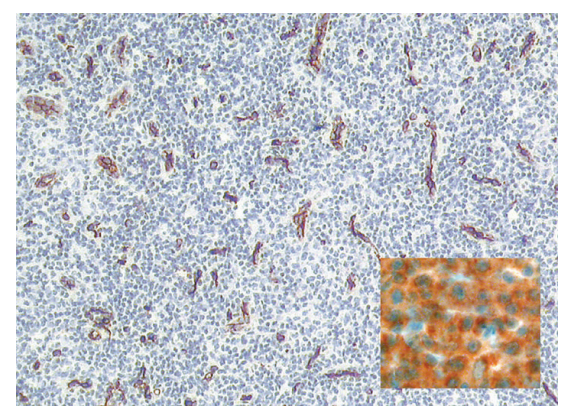

(b)

Figure 3: (a) Microvascular organization of the cortical (B-cell-) zone of a normal lymph node highlighted by CD34; note a perifollicular condensation of microvessels and paucity inside the follicle. (b) Increased microvessel density in a mantle cell lymphoma case; insert: vascular endothelial growth factor expression in a diffuse large B-cell lymphoma case highlighted by immunohistochemistry.

Regarding MVD, follicular lymphoma is of special interest. Several studies have recognized increased vascularization in the perifollicular compartment of affected lymph nodes $[35,111,113,125]$. The MVD inside the neoplastic follicles seems similar to that in reactive lymph nodes and somewhat lower than in DLBCL and MCL. Koster and Raemaekers [113] showed that in follicular lymphoma, increased vascularization is associated with improved clinical outcome. Furthermore, VEGF expression seemed not to be involved in follicular lymphoma angiogenesis.

In T-cell lymphomas, the VEGF gene is overexpressed in both microdissected lymphoma- and endothelial cells of angioimmunoblastic T-cell lymphoma (AITL) [126]. Accordingly, VEGF protein expression was also found in both types of cells in lymph nodes and bone marrow samples with AITL involvement.

In Hodgkin lymphoma (HL), VEGF is expressed along with HIF-1, VEGFR-2, and platelet-derived endothelial growth factor (PDGF) and its receptor (PDGFR $\alpha$ ) at both the protein and RNA levels [127, 128]. MVD seems also to be increased in HL, especially in progressive disease [128].

6.1. Antiangiogenic Therapy in Lymphomas. Given the low proportion of DLBCL cases strongly expressing VEGF and 
the lack of correlation between VEGF and MVD in DLBCL, it could be anticipated that bevacizumab application in DLBCL would be not very successful, explaining the low observed response rates. In a phase II study of the Southwest oncology group, single agent bevacizumab was examined in 52 DLBCL or MCL patients in first or second relapses of aggressive lymphomas [129]. Patients were treated with bevacizumab at $10 \mathrm{mg} / \mathrm{kg}$ every 2 weeks, resulting in a sixmonth progression-free survival of $16 \%$ with a response rate of $2 \%$, and median duration of response or stable disease of 5.2 months (range 3.5-72.7). Treatment was generally well tolerated, with grade 3 hypertension being the most significant adverse side effect in two patients. Clinical trials combining active chemotherapy regimens with VEGFtargeted agents are currently in progress. Thalidomide was evaluated in a study of 19 patients with recurrent/refractory lymphomas until disease progression or prohibitive toxicity was observed [130]. One patient (5\%) with evidence of recurrent gastric mucosa-associated lymphoid tissue B-cell lymphoma achieved CR, and 3 patients (16\%) achieved stable disease. There is more promising data with lenalidomide treatment of indolent lymphomas, including follicular lymphoma [131, 132], with reported response rates about $30 \%$ in pretreated patients, but the significance of lenalidomide effects other than modulation of angiogenesis, for example, immunomodulation, should be considered in this instance.

Given this strong VEGF production in AITL, it is not surprising that the results of anti-angiogenesis therapy in relapsed AITL are promising. There are published case reports $[133,134]$ with successful bevacizumab treatment in AITL leading to remissions lasting for several months. One patient received 4th line bevacizumab leading to CR lasting for 10 months; another received 5th line bevacizumab leading to $\mathrm{CR}$ with such excellent tolerability that an allogeneic transplant could be planned. Furthermore, there is additional small, but promising, body of evidence in favor of thalidomide [135-137] and lenalidomide [http://www.org/ ASCOv2/Meetings/Abstracts?\&vmview=abst_detail_view\& $\mathrm{ID}=65$ \&abstractID=30959]. In peripheral T-cell lymphoma, antiangiogenic substances are not yet integrated in primary, curative-intended therapies. In the relapsed, palliative setting, however, there are some promising data, especially with lenalidomide $(25 \mathrm{mg} / \mathrm{d}$ during 3 weeks in a 4 -week cycle) [138], including unpublished data on 24 T-cell lymphomas, including 7 patients with AITL [http://www.asco.org/ASCOv2/Meetings/Abstracts? \&vmview=abst_detail_ view\&confID $=65 \&$ abstractID $=30959]$. In these heavily pretreated patients, the response rate was $30 \%$, and long-lasting remissions were also observed in the responding patients.

After a successful tumor growth delay by bevacizumab administration in a xenograft HL model, Reiners et al. also showed some promising effects of combined gemcitabine/bevacizumab regimen in heavily pretreated HL patients with multiple relapses [139]. In a combination study, thalidomide was examined with vinblastine in patients with refractory HL [140]; of the 11 patients, 4 showed a partial response to treatment (response rate $36 \%$ ) and two patients had stable disease.

\section{Conclusion}

Angiogenesis is essential to the development of hematolymphoid malignancies, including acute and chronic leuk emias, MPN, and lymphomas. In such instances, VEGF/VEGFR-related pathways are the most relevant regulators of neoangiogenesis, vasculogenesis, and recruitment of endothelial progenitor cells. Furthermore, VEGF/VEGFR interactions can stimulate proliferation, migration, and survival of leukemia/lymphoma cells by autocrine and paracrine loops. Finally, in some hemato-lymphoid neoplasms, VEGF/VEGFR-related pathways represent a promising therapeutic target.

\section{Abbreviations}

AML: Acute myelogenous leukemia

DLBCL: Diffuse large B-cell lymphoma

CLL: Chronic lymphocytic leukemia

NHL: Non-Hodgkin lymphoma

NSCLC: Nonsmall cell lung cancer

MDS: Myelodysplastic syndrome

MM: Multiple myeloma

MPN: Myeloproliferative neoplasm

PDGFR: Platelet derived growth factor receptor

PMF: $\quad$ Primary myelofibrosis

RTK: Receptor tyrosine kinase

VEGF: Vascular endothelial growth factor (receptor).

\section{References}

[1] J. Folkman, "Angiogenesis in cancer, vascular, rheumatoid and other disease," Nature Medicine, vol. 1, no. 1, pp. 27-31, 1995.

[2] J. Folkman, "Tumor angiogenesis: therapeutic implications," The New England Journal of Medicine, vol. 285, no. 21, pp. 1182-1186, 1971.

[3] D. Lyden, K. Hattori, S. Dias, et al., "Impaired recruitment of bone-marrow-derived endothelial and hematopoietic precursor cells blocks tumor angiogenesis and growth," Nature Medicine, vol. 7, no. 11, pp. 1194-1201, 2001.

[4] S. Rafii, D. Lyden, R. Benezra, K. Hattori, and B. Heissig, "Vascular and haematopoietic stem cells: novel targets for anti-angiogenesis therapy?" Nature Reviews Cancer, vol. 2, no. 11 , pp. 826-835, 2002.

[5] B. A. Peters, L. A. Diaz Jr., K. Polyak, et al., "Contribution of bone marrow-derived endothelial cells to human tumor vasculature," Nature Medicine, vol. 11, no. 3, pp. 261-262, 2005.

[6] D. Shweiki, A. Itin, D. Soffer, and E. Keshet, "Vascular endothelial growth factor induced by hypoxia may mediate hypoxia-initiated angiogenesis," Nature, vol. 359, no. 6398, pp. 843-845, 1992.

[7] Y. Dor, R. Porat, and E. Keshet, "Vascular endothelial growth factor and vascular adjustments to perturbations in oxygen homeostasis," American Journal of Physiology, vol. 280, no. 6, pp. C1367-C1374, 2001.

[8] M. Ryuto, M. Ono, H. Izumi, et al., "Induction of vascular endothelial growth factor by tumor necrosis factor $\alpha$ in human glioma cells: possible roles of SP-1," Journal of Biological Chemistry, vol. 271, no. 45, pp. 28220-28228, 1996. 
[9] L. Pertovaara, A. Kaipainen, T. Mustonen, et al., "Vascular endothelial growth factor is induced in response to transforming growth factor- $\beta$ in fibroblastic and epithelial cells," Journal of Biological Chemistry, vol. 269, no. 9, pp. 62716274, 1994.

[10] W. G. Kaelin Jr., "The von Hippel-Lindau tumor suppressor protein and clear cell renal carcinoma," Clinical Cancer Research, vol. 13, no. 2, pp. 680s-682s, 2007.

[11] X. Dong, Z. C. Han, and R. Yang, "Angiogenesis and antiangiogenic therapy in hematologic malignancies," Critical Reviews in Oncology/Hematology, vol. 62, no. 2, pp. 105$118,2007$.

[12] J. L. Frater, N. E. Kay, C. L. Goolsby, S. E. Crawford, G. W. Dewald, and L. C. Peterson, "Dysregulated angiogenesis in B-chronic lymphocytic leukemia: morphologic, immunohistochemical, and flow cytometric evidence," Diagnostic Pathology, vol. 3, no. 1, article 16, 2008.

[13] N. Ferrara, H.-P. Gerber, and J. LeCouter, "The biology of VEGF and its receptors," Nature Medicine, vol. 9, no. 6, pp. 669-676, 2003.

[14] H. Gille, J. Kowalski, B. Li, et al., "Analysis of biological effects and signaling properties of Flt-1 (VEGFR-1) and KDR (VEGFR-2): a reassessment using novel receptorspecific vascular endothelial growth factor mutants," Journal of Biological Chemistry, vol. 276, no. 5, pp. 3222-3230, 2001.

[15] K. Hattori, S. Dias, B. Heissig, et al., "Vascular endothelial growth factor and angiopoietin-1 stimulate postnatal hematopoiesis by recruitment of vasculogenic and hematopoietic stem cells," Journal of Experimental Medicine, vol. 193, no. 9, pp. 1005-1014, 2001.

[16] W. T. Bellamy, L. Richter, Y. Frutiger, and T. M. Grogan, "Expression of vascular endothelial growth factor and its receptors in hematopoietic malignancies," Cancer Research, vol. 59, no. 3, pp. 728-733, 1999.

[17] M. Gill, S. Dias, K. Hattori, et al., "Vascular trauma induces rapid but transient mobilization of VEGFR2 ${ }^{+} \mathrm{AC} 133^{+}$ endothelial precursor cells," Circulation Research, vol. 88, no. 2, pp. 167-174, 2001.

[18] I. Casella, T. Feccia, C. Chelucci, et al., "Autocrine-paracrine VEGF loops potentiate the maturation of megakaryocytic precursors through Flt1 receptor," Blood, vol. 101, no. 4, pp. 1316-1323, 2003.

[19] M. Autiero, A. Luttun, M. Tjwa, and P. Carmeliet, "Placental growth factor and its receptor, vascular endothelial growth factor receptor-1: novel targets for stimulation of ischemic tissue revascularization and inhibition of angiogenic and inflammatory disorders," Journal of Thrombosis and Haemostasis, vol. 1, no. 7, pp. 1356-1370, 2003.

[20] K. J. Kim, B. Li, J. Winer, et al., "Inhibition of vascular endothelial growth factor-induced angiogenesis suppresses tumour growth in vivo," Nature, vol. 362, no. 6423, pp. 841844, 1993.

[21] W. Risau, "Mechanisms of angiogenesis," Nature, vol. 386, no. 6626, pp. 671-674, 1997.

[22] M. Benouchan and B. M. Colombo, "Anti-angiogenic strategies for cancer therapy," International Journal of Oncology, vol. 27, no. 2, pp. 563-571, 2005.

[23] H. Hurwitz, L. Fehrenbacher, W. Novotny, et al., "Bevacizumab plus irinotecan, fluorouracil, and leucovorin for metastatic colorectal cancer," The New England Journal of Medicine, vol. 350, no. 23, pp. 2335-2342, 2004.

[24] A. Sandler, R. Gray, M. C. Perry, et al., "Paclitaxel-carboplatin alone or with bevacizumab for non-small-cell lung cancer,"
The New England Journal of Medicine, vol. 355, no. 24, pp. 2542-2550, 2006.

[25] K. Miller, M. Wang, J. Gralow, et al., "Paclitaxel plus bevacizumab versus paclitaxel alone for metastatic breast cancer," The New England Journal of Medicine, vol. 357, no. 26, pp. 2666-2676, 2007.

[26] J. E. Karp, I. Gojo, R. Pili, et al., "Targeting vascular endothelial growth factor for relapsed and refractory adult acute myelogenous leukemias: therapy with sequential $1-\beta-D-$ arabinofuranosylcytosine, mitoxantrone, and bevacizumab," Clinical Cancer Research, vol. 10, no. 11, pp. 3577-3585, 2004.

[27] B. Escudier, T. Eisen, W. M. Stadler, et al., "Sorafenib in advanced clear-cell renal-cell carcinoma," The New England Journal of Medicine, vol. 356, no. 2, pp. 125-134, 2007.

[28] R. J. Motzer, T. E. Hutson, P. Tomczak, et al., "Sunitinib versus interferon alfa in metastatic renal-cell carcinoma," The New England Journal of Medicine, vol. 356, no. 2, pp. 115-124, 2007.

[29] A. Aguayo, "The role of angiogenesis in the biology and therapy of myelodysplastic syndromes," Current Hematology Reports, vol. 3, no. 3, pp. 184-191, 2004.

[30] M. Medinger, R. Skoda, A. Gratwohl, et al., "Angiogenesis and vascular endothelial growth factor-/receptor expression in myeloproliferative neoplasms: correlation with clinical parameters and JAK2-V617F mutational status," British Journal of Haematology, vol. 146, no. 2, pp. 150-157, 2009.

[31] T. Padró, S. Ruiz, R. Bieker, et al., "Increased angiogenesis in the bone marrow of patients with acute myeloid leukemia," Blood, vol. 95, no. 8, pp. 2637-2644, 2000.

[32] G. Pruneri, F. Bertolini, D. Soligo, et al., "Angiogenesis in myelodysplastic syndromes," British Journal of Cancer, vol. 81, no. 8, pp. 1398-1401, 1999.

[33] M. Steurer, H. Zoller, F. Augustin, et al., "Increased angiogenesis in chronic idiopathic myelofibrosis: vascular endothelial growth factor as a prominent angiogenic factor," Human Pathology, vol. 38, no. 7, pp. 1057-1064, 2007.

[34] G. Stifter, S. Heiss, G. Gastl, A. Tzankov, and R. Stauder, "Over-expression of tumor necrosis factor-alpha in bone marrow biopsies from patients with myelodysplastic syndromes: relationship to anemia and prognosis," European Journal of Haematology, vol. 75, no. 6, pp. 485-491, 2005.

[35] A. Tzankov, S. Heiss, S. Ebner, et al., "Angiogenesis in nodal B cell lymphomas: a high throughput study," Journal of Clinical Pathology, vol. 60, no. 5, pp. 476-482, 2007.

[36] A. Vacca, D. Ribatti, L. Roncali, et al., "Bone marrow angiogenesis and progression in multiple myeloma," British Journal of Haematology, vol. 87, no. 3, pp. 503-508, 1994.

[37] M. Majka, A. Janowska-Wieczorek, J. Ratajczak, et al., "Numerous growth factors, cytokines, and chemokines are secreted by human $\mathrm{CD}^{+} 4^{+}$cells, myeloblasts, erythroblasts, and megakaryoblasts and regulate normal hematopoiesis in an autocrine/paracrine manner," Blood, vol. 97, no. 10, pp. 3075-3085, 2001.

[38] S. Dias, K. Hattori, B. Heissig, et al., "Inhibition of both paracrine and autocrine VEGF/VEGFR-2 signaling pathways is essential to induce long-term remission of xenotransplanted human leukemias," Proceedings of the National Academy of Sciences of the United States of America, vol. 98, no. 19, pp. 10857-10862, 2001.

[39] S. Loges, G. Heil, M. Bruweleit, et al., "Analysis of concerted expression of angiogenic growth factors in acute myeloid leukemia: expression of angiopoietin-2 represents an independent prognostic factor for overall survival," Journal of Clinical Oncology, vol. 23, no. 6, pp. 1109-1117, 2005. 
[40] D. W. Leung, G. Cachianes, W.-J. Kuang, D. V. Goeddel, and N. Ferrara, "Vascular endothelial growth factor is a secreted angiogenic mitogen," Science, vol. 246, no. 4935, pp. 1306 1309, 1989.

[41] A. R. Perez-Atayde, S. E. Sallan, U. Tedrow, S. Connors, E. Allred, and J. Folkman, "Spectrum of tumor angiogenesis in the bone marrow of children with acute lymphoblastic leukemia," American Journal of Pathology, vol. 150, no. 3, pp. 815-821, 1997.

[42] S. Yetgin, I. Yenicesu, M. Çetin, and M. Tuncer, "Clinical importance of serum vascular endothelial and basic fibroblast growth factors in children with acute lymphoblastic leukemia," Leukemia \& Lymphoma, vol. 42, no. 1-2, pp. 83$88,2001$.

[43] D. Hanahan and J. Folkman, "Patterns and emerging mechanisms of the angiogenic switch during tumorigenesis," Cell, vol. 86, no. 3, pp. 353-364, 1996.

[44] U. Norén-Nyström, M. Heyman, P. Frisk, et al., "Vascular density in childhood acute lymphoblastic leukaemia correlates to biological factors and outcome," British Journal of Haematology, vol. 146, no. 5, pp. 521-530, 2009.

[45] A. Aguayo, H. M. Kantarjian, E. H. Estey, et al., "Plasma vascular endothelial growth factor levels have prognostic significance in patients with acute myeloid leukemia but not in patients with myelodysplastic syndromes," Cancer, vol. 95, no. 9, pp. 1923-1930, 2002.

[46] A. Aguayo, E. Estey, H. Kantarjian, et al., "Cellular vascular endothelial growth factor is a predictor of outcome in patients with acute myeloid leukemia," Blood, vol. 94, no. 11, pp. 3717-3721, 1999.

[47] W. Fiedler, U. Graeven, S. Ergün, et al., "Vascular endothelial growth factor, a possible paracrine growth factor in human acute myeloid leukemia," Blood, vol. 89, no. 6, pp. 1870-1875, 1997.

[48] H. Chen, A. T. Treweeke, D. C. West, et al., "In vitro and in vivo production of vascular endothelial growth factor by chronic lymphocytic leukemia cells," Blood, vol. 96, no. 9, pp. 3181-3187, 2000.

[49] S. Dias, K. Hattori, Z. Zhu, et al., "Autocrine stimulation of VEGFR-2 activates human leukemic cell growth and migration," Journal of Clinical Investigation, vol. 106, no. 4, pp. 511-521, 2000.

[50] Q. Hu, A. L. Dey, Y. Yang, et al., "Soluble vascular endothelial growth factor receptor 1 , and not receptor 2 , is an independent prognostic factor in acute myeloid leukemia and myelodysplastic syndromes," Cancer, vol. 100, no. 9, pp. 1884-1891, 2004.

[51] R. Lai, E. Estey, Y. Shen, et al., "Clinical significance of plasma endostatin in acute myeloid leukemia/myelodysplastic syndrome," Cancer, vol. 94, no. 1, pp. 14-17, 2002.

[52] W. T. Bellamy, "Expression of vascular endothelial growth factor and its receptors in multiple myeloma and other hematopoietic malignancies," Seminars in Oncology, vol. 28, no. 6 , pp. 551-559, 2001.

[53] M. Allouche, F. Bayard, S. Clamens, G. Fillola, P. Sie, and F. Amalric, "Expression of basic fibroblast growth factor (bFGF) and FCF-receptors in human leukemic cells," Leukemia, vol. 9, no. 1, pp. 77-86, 1995.

[54] H.-P. Gerber, A. K. Malik, G. P. Solar, et al., "VEGF regulates haematopoietic stem cell survival by an internal autocrine loop mechanism," Nature, vol. 417, no. 6892, pp. 954-958, 2002.

[55] L. G. Presta, H. Chen, S. J. O'Connor, et al., "Humanization of an anti-vascular endothelial growth factor monoclonal antibody for the therapy of solid tumors and other disorders," Cancer Research, vol. 57, no. 20, pp. 4593-4599, 1997.

[56] B. Moncada, M. L. Baranda, R. González-Amaro, R. Urbina, and C. E. Loredo, "Thalidomide-effect on T cell subsets as a possible mechanism of action," International Journal of Leprosy, vol. 53, no. 2, pp. 201-205, 1985.

[57] R. J. D'Amato, M. S. Loughnan, E. Flynn, and J. Folkman, "Thalidomide is an inhibitor of angiogenesis," Proceedings of the National Academy of Sciences of the United States of America, vol. 91, no. 9, pp. 4082-4085, 1994.

[58] D. Gupta, S. P. Treon, Y. Shima, et al., "Adherence of multiple myeloma cells to bone marrow stromal cells upregulates vascular endothelial growth factor secretion: therapeutic applications," Leukemia, vol. 15, no. 12, pp. 1950-1961, 2001.

[59] S. K. Teo, "Properties of thalidomide and its analogues: implications for anticancer therapy," AAPS Journal, vol. 7, no. 1, pp. E14-E19, 2005.

[60] K. Dredge, J. B. Marriott, C. D. Macdonald, et al., "Novel thalidomide analogues display anti-angiogenic activity independently of immunomodulatory effects," British Journal of Cancer, vol. 87, no. 10, pp. 1166-1172, 2002.

[61] D. A. Thomas, E. Estey, F. J. Giles, et al., "Single agent thalidomide in patients with relapsed or refractory acute myeloid leukaemia," British Journal of Haematology, vol. 123, no. 3, pp. 436-441, 2003.

[62] M. B. Steins, T. Padró, R. Bieker, et al., "Efficacy and safety of thalidomide in patients with acute myeloid leukemia," Blood, vol. 99, no. 3, pp. 834-839, 2002.

[63] P. Barr, P. Fu, H. Lazarus, et al., "Antiangiogenic activity of thalidomide in combination with fludarabine, carboplatin, and topotecan for high-risk acute myelogenous leukemia," Leukemia \& Lymphoma, vol. 48, no. 10, pp. 1940-1949, 2007.

[64] J. Drevs, R. Müller-Driver, C. Wittig, et al., "PTK787/ZK 222584, a specific vascular endothelial growth factor-receptor tyrosine kinase inhibitor, affects the anatomy of the tumor vascular bed and the functional vascular properties as detected by dynamic enhanced magnetic resonance imaging," Cancer Research, vol. 62, no. 14, pp. 4015-4022, 2002.

[65] K. Mross, J. Drevs, M. Müller, et al., "Phase I clinical and pharmacokinetic study of PTK/ZK, a multiple VEGF receptor inhibitor, in patients with liver metastases from solid tumours," European Journal of Cancer, vol. 41, no. 9, pp. 1291-1299, 2005.

[66] J. M. Wood, G. Bold, E. Buchdunger, et al., "PTK787/ZK 222584, a novel and potent inhibitor of vascular endothelial growth factor receptor tyrosine kinases, impairs vascular endothelial growth factor-induced responses and tumor growth after oral administration," Cancer Research, vol. 60, no. 8, pp. 2178-2189, 2000.

[67] B. Lin, K. Podar, D. Gupta, et al., "The vascular endothelial growth factor receptor tyrosine kinase inhibitor PTK787/ZK222584 inhibits growth and migration of multiple myeloma cells in the bone marrow microenvironment," Cancer Research, vol. 62, no. 17, pp. 5019-5026, 2002.

[68] G. J. Roboz, F. J. Giles, A. F. List, et al., "Phase 1 study of PTK787/ZK 222584, a small molecule tyrosine kinase receptor inhibitor, for the treatment of acute myeloid leukemia and myelodysplastic syndrome," Leukemia, vol. 20, no. 6, pp. 952957, 2006.

[69] N. Barbarroja, L. A. Torres, M. J. Luque, et al., "Additive effect of PTK787/ZK 222584, a potent inhibitor of VEGFR phosphorylation, with Idarubicin in the treatment of acute 
myeloid leukemia," Experimental Hematology, vol. 37, no. 6, pp. 679-691, 2009.

[70] S. R. Wedge, J. Kendrew, L. F. Hennequin, et al., “AZD2171: a highly potent, orally bioavailable, vascular endothelial growth factor receptor-2 tyrosine kinase inhibitor for the treatment of cancer," Cancer Research, vol. 65, no. 10, pp. 4389-4400, 2005.

[71] J. Drevs, P. Siegert, M. Medinger, et al., "Phase I clinical study of AZD2171, an oral vascular endothelial growth factor signaling inhibitor, in patients with advanced solid tumors," Journal of Clinical Oncology, vol. 25, no. 21, pp. 3045-3054, 2007.

[72] W. Fiedler, R. Mesters, M. Heuser, et al., "An open-label, phase I study of cediranib (RECENTIN ${ }^{\mathrm{TM}}$ ) in patients with acute myeloid leukemia," Leukemia Research, vol. 34, no. 2, pp. 196-202, 2010.

[73] B. Brunner, E. Gunsilius, P. Schumacher, H. Zwierzina, G. Gastl, and R. Stauder, "Blood levels of angiogenin and vascular endothelial growth factor are elevated in myelodysplastic syndromes and in acute myeloid leukemia," Journal of Hematotherapy and Stem Cell Research, vol. 11, no. 1, pp. 119-125, 2002.

[74] F. Wimazal, M.-T. Krauth, A. Vales, et al., "Immunohistochemical detection of vascular endothelial growth factor (VEGF) in the bone marrow in patients with myelodysplastic syndromes: correlation between VEGF expression and the FAB category," Leukemia \& Lymphoma, vol. 47, no. 3, pp. 451-460, 2006.

[75] P. Musto, "Thalidomide therapy for myelodysplastic syndromes: current status and future perspectives," Leukemia Research, vol. 28, no. 4, pp. 325-332, 2004.

[76] A. Raza, M. Mehdi, M. Mumtaz, F. Ali, S. Lascher, and N. Galili, "Combination of 5-azacytidine and thalidomide for the treatment of myelodysplastic syndromes and acute myeloid leukemia," Cancer, vol. 113, no. 7, pp. 1596-1604, 2008.

[77] V. Kotla, S. Goel, S. Nischal, et al., "Mechanism of action of lenalidomide in hematological malignancies," Journal of Hematology and Oncology, vol. 2, article 36, 2009.

[78] A. List, G. Dewald, J. Bennett, et al., "Lenalidomide in the myelodysplastic syndrome with chromosome 5q deletion," The New England Journal of Medicine, vol. 355, no. 14, pp. 1456-1465, 2006.

[79] A. M. Roccaro, T. Hideshima, N. Raje, et al., "Bortezomib mediates antiangiogenesis in multiple myeloma via direct and indirect effects on endothelial cells," Cancer Research, vol. 66, no. 1, pp. 184-191, 2006.

[80] O. Sezer, K. Niemöller, J. Eucker, et al., "Bone marrow microvessel density is a prognostic factor for survival in patients with multiple myeloma," Annals of Hematology, vol. 79, no. 10, pp. 574-577, 2000.

[81] S. V. Rajkumar, T. Leong, P. C. Roche, et al., "Prognostic value of bone marrow angiogenesis in multiple myeloma," Clinical Cancer Research, vol. 6, no. 8, pp. 3111-3116, 2000.

[82] N. C. Munshi and C. Wilson, "Increased bone marrow microvessel density in newly diagnosed multiple myeloma carries a poor prognosis," Seminars in Oncology, vol. 28, no. 6, pp. 565-569, 2001.

[83] S. Kumar, T. E. Witzig, M. Timm, et al., "Expression of VEGF and its receptors by myeloma cells," Leukemia, vol. 17, no. 10, pp. 2025-2031, 2003.
[84] K. Podar, Y.-T. Tai, F. E. Davies, et al., "Vascular endothelial growth factor triggers signaling cascades mediating multiple myeloma cell growth and migration," Blood, vol. 98, no. 2, pp. 428-435, 2001.

[85] B. Dankbar, T. Padró, R. Leo, et al., "Vascular endothelial growth factor and interleukin-6 in paracrine tumor-stromal cell interactions in multiple myeloma," Blood, vol. 95, no. 8, pp. 2630-2636, 2000.

[86] S. V. Rajkumar, R. A. Mesa, and A. Tefferi, "A review of angiogenesis and anti-angiogenic therapy in hematologic malignancies," Journal of Hematotherapy and Stem Cell Research, vol. 11, no. 1, pp. 33-47, 2002.

[87] S. Kumar, T. E. Witzig, M. Timm, et al., "Bone marrow angiogenic ability and expression of angiogenic cytokines in myeloma: evidence favoring loss of marrow angiogenesis inhibitory activity with disease progression," Blood, vol. 104, no. 4, pp. 1159-1165, 2004.

[88] L. Pour, H. Svachova, Z. Adam, et al., "Levels of angiogenic factors in patients with multiple myeloma correlate with treatment response," Annals of Hematology, vol. 89, no. 4, pp. 385-389, 2010.

[89] S. Singhal, J. Mehta, R. Desikan, et al., "Antitumor activity of thalidomide in refractory multiple myeloma," The New England Journal of Medicine, vol. 341, no. 21, pp. 1565-1571, 1999.

[90] B. Barlogie, R. Desikan, P. Eddlemon, et al., "Extended survival in advanced and refractory multiple myeloma after single-agent thalidomide: identification of prognostic factors in a phase 2 study of 169 patients," Blood, vol. 98, no. 2, pp. 492-494, 2001.

[91] S. V. Rajkumar, E. Blood, D. Vesole, R. Fonseca, and P. R. Greipp, "Phase III clinical trial of thalidomide plus dexamethasone compared with dexamethasone alone in newly diagnosed multiple myeloma: a clinical trial coordinated by the Eastern Cooperative Oncology Group," Journal of Clinical Oncology, vol. 24, no. 3, pp. 431-436, 2006.

[92] M. Dimopoulos, A. Spencer, M. Attal, et al., "Lenalidomide plus dexamethasone for relapsed or refractory multiple myeloma," The New England Journal of Medicine, vol. 357, no. 21, pp. 2123-2132, 2007.

[93] D. M. Weber, C. Chen, R. Niesvizky, et al., "Lenalidomide plus dexamethasone for relapsed multiple myeloma in North America," The New England Journal of Medicine, vol. 357, no. 21, pp. 2133-2142, 2007.

[94] L. G. Lundberg, R. Lerner, P. Sundelin, R. Rogers, J. Folkman, and J. Palmblad, "Bone marrow in polycythemia vera, chronic myelocytic leukemia, and myelofibrosis has an increased vascularity," American Journal of Pathology, vol. 157, no. 1, pp. 15-19, 2000.

[95] E. Zetterberg, L. G. Lundberg, and J. Palmblad, "Characterization of blood vessels in bone marrow from patients with chronic myeloid leukemia and polycythemia vera," Scandinavian Journal of Clinical and Laboratory Investigation, vol. 64, no. 7, pp. 641-647, 2004.

[96] T. Wróbel, G. Mazur, P. Surowiak, D. Wołowiec, M. Jeleñ, and K. Kuliczkowski, "Increased expression of vascular endothelial growth factor (VEGF) in bone marrow of patients with myeloproliferative disorders (MPD)," Pathology and Oncology Research, vol. 9, no. 3, pp. 170-173, 2003.

[97] M. Ponzoni, D. G. Savage, A. J. M. Ferreri, et al., "Chronic idiopathic myelofibrosis: independent prognostic importance of bone marrow microvascular density evaluated by CD105 (endoglin) immunostaining," Modern Pathology, vol. 17, no. 12, pp. 1513-1520, 2004. 
[98] R. Kralovics, F. Passamonti, A. S. Buser, et al., "A gain-offunction mutation of JAK2 in myeloproliferative disorders," The New England Journal of Medicine, vol. 352, no. 17, pp. 1779-1790, 2005.

[99] R. Kralovics, S.-S. Teo, S. Li, et al., "Acquisition of the V617F mutation of JAK2 is a late genetic event in a subset of patients with myeloproliferative disorders," Blood, vol. 108, no. 4, pp. 1377-1380, 2006.

[100] E. Boveri, F. Passamonti, E. Rumi, et al., "Bone marrow microvessel density in chronic myeloproliferative disorders: a study of 115 patients with clinicopathological and molecular correlations," British Journal of Haematology, vol. 140, no. 2, pp. 162-168, 2008.

[101] U. Gianelli, C. Vener, P. R. Raviele, et al., "VEGF expression correlates with microvessel density in Philadelphia chromosome-negative chronic myeloproliferative disorders," American Journal of Clinical Pathology, vol. 128, no. 6, pp. 966-973, 2007.

[102] K. Zhu, M. A. Amin, Y. Zha, L. A. Harlow, and A. E. Koch, "Mechanism by which $\mathrm{H}-2 \mathrm{~g}$, a glucose analog of blood group $\mathrm{H}$ antigen, mediates angiogenesis," Blood, vol. 105, no. 6, pp. 2343-2349, 2005.

[103] A. C. Dudley, D. Thomas, J. Best, and A. Jenkins, "A VEGF/JAK2/STAT5 axis may partially mediate endothelial cell tolerance to hypoxia," Biochemical Journal, vol. 390, no. 2, pp. 427-436, 2005.

[104] S. Sozer, M. I. Fiel, T. Schiano, M. Xu, J. Mascarenhas, and R. Hoffman, "The presence of JAK2V617F mutation in the liver endothelial cells of patients with Budd-Chiari syndrome," Blood, vol. 113, no. 21, pp. 5246-5249, 2009.

[105] D. A. Thomas, F. J. Giles, M. Albitar, et al., "Thalidomide therapy for myelofibrosis with myeloid metaplasia," Cancer, vol. 106, no. 9, pp. 1974-1984, 2006.

[106] J.-F. Abgrall, I. Guibaud, J.-N. Bastie, et al., "Thalidomide versus placebo in myeloid metaplasia with myelofibrosis: a prospective, randomized, double-blind, multicenter study," Haematologica, vol. 91, no. 8, pp. 1027-1032, 2006.

[107] A. Tefferi, J. Cortes, S. Verstovsek, et al., "Lenalidomide therapy in myelofibrosis with myeloid metaplasia," Blood, vol. 108, no. 4, pp. 1158-1164, 2006.

[108] A. Quintás-Cardama, H. M. Kantarjian, T. Manshouri, et al., "Lenalidomide plus prednisone results in durable clinical, histopathologic, and molecular responses in patients with myelofibrosis," Journal of Clinical Oncology, vol. 27, no. 28, pp. 4760-4766, 2009.

[109] F. J. Giles, A. F. List, M. Carroll, et al., "PTK787/ZK 222584, a small molecule tyrosine kinase receptor inhibitor of vascular endothelial growth factor (VEGF), has modest activity in myelofibrosis with myeloid metaplasia," Leukemia Research, vol. 31, no. 7, pp. 891-897, 2007.

[110] D. Ribatti, A. Vacca, B. Nico, M. Fanelli, L. Roncali, and F. Dammacco, "Angiogenesis spectrum in the stroma of B-cell non-Hodgkin's lymphomas. An immunohistochemical and ultrastructural study," European Journal of Haematology, vol. 56, no. 1-2, pp. 45-53, 1996.

[111] A. Vacca, D. Ribatti, L. Ruco, et al., "Angiogenesis extent and macrophage density increase simultaneously with pathological progression in B-cell non-Hodgkin's lymphomas," British Journal of Cancer, vol. 79, no. 5-6, pp. 965-970, 1999.

[112] V. Arias and F. A. Soares, "Vascular density (tumor angiogenesis) in non-Hodgkin's lymphomas and florid follicular hyperplasia: a morphometric study," Leukemia \& Lymphoma, vol. 40, no. 1-2, pp. 157-166, 2001.
[113] A. Koster and J. M. M. Raemaekers, "Angiogenesis in malignant lymphoma," Current Opinion in Oncology, vol. 17, no. 6, pp. 611-616, 2005.

[114] A. Vacca, S. Moretti, D. Ribatti, et al., "Progression of mycosis fungoides is associated with changes in angiogenesis and expression of the matrix metalloproteinases 2 and 9," European Journal of Cancer, vol. 33, no. 10, pp. 1685-1692, 1997.

[115] L. Schaerer, M. H. Schmid, B. Mueller, R. G. Dummer, G. Burg, and W. Kempf, "Angiogenesis in cutaneous lymphoproliferative disorders. Microvessel density discriminates between cutaneous B-cell lymphomas and B-cell pseudolymphomas," American Journal of Dermatopathology, vol. 22, no. 2, pp. 140-143, 2000.

[116] G. Mazur, Z. Woźniak, T. Wróbel, J. Maj, and K. Kuliczkowski, "Increased angiogenesis in cutaneous T-cell lymphomas," Pathology and Oncology Research, vol. 10, no. 1, pp. 34-36, 2004.

[117] E. Passalidou, M. Stewart, M. Trivella, et al., "Vascular patterns in reactive lymphoid tissue and in non-Hodgkin's lymphoma," British Journal of Cancer, vol. 88, no. 4, pp. 553559, 2003.

[118] B. Streubel, A. Chott, D. Huber, et al., "Lymphoma-specific genetic aberrations in microvascular endothelial cells in Bcell lymphomas," The New England Journal of Medicine, vol. 351, no. 3, pp. 250-259, 2004.

[119] J. Ruan, K. Hajjar, S. Rafii, and J. P. Leonard, "Angiogenesis and antiangiogenic therapy in non-Hodgkin's lymphoma," Annals of Oncology, vol. 20, no. 3, pp. 413-424, 2009.

[120] S. S. Dave, G. Wright, B. Tan, et al., "Prediction of survival in follicular lymphoma based on molecular features of tumor-infiltrating immune cells," The New England Journal of Medicine, vol. 351, no. 21, pp. 2159-2169, 2004.

[121] G. Lenz, G. Wright, S. S. Dave, et al., "Stromal gene signatures in large-B-cell lymphomas," The New England Journal of Medicine, vol. 359, no. 22, pp. 2313-2323, 2008.

[122] C.-L. Ho, L.-F. Sheu, and C.-Y. Li, "Immunohistochemical expression of basic fibroblast growth factor, vascular endothelial growth factor, and their receptors in stage IV non-Hodgkin lymphoma," Applied Immunohistochemistry and Molecular Morphology, vol. 10, no. 4, pp. 316-321, 2002.

[123] P. Salven, A. Orpana, L. Teerenhovi, and H. Joensuu, "Simultaneous elevation in the serum concentrations of the angiogenic growth factors VEGF and bFGF is an independent predictor of poor prognosis in non-Hodgkin lymphoma: a single-institution study of 200 patients," Blood, vol. 96, no. 12, pp. 3712-3718, 2000.

[124] D. Gratzinger, S. Zhao, R. J. Tibshirani, et al., "Prognostic significance of VEGF, VEGF receptors, and microvessel density in diffuse large B cell lymphoma treated with anthracyclinebased chemotherapy," Laboratory Investigation, vol. 88, no. 1, pp. 38-47, 2008.

[125] J. M. Jørgensen, F. B. Sørensen, K. Bendix, et al., "Angiogenesis in non-Hodgkin's lymphoma: clinico-pathological correlations and prognostic significance in specific subtypes," Leukemia \& Lymphoma, vol. 48, no. 3, pp. 584-595, 2007.

[126] W.-L. Zhao, S. Mourah, N. Mounier, et al., "Vascular endothelial growth factor-A is expressed both on lymphoma cells and endothelial cells in angioimmunoblastic T-cell lymphoma and related to lymphoma progression," Laboratory Investigation, vol. 84, no. 11, pp. 1512-1519, 2004.

[127] I. A. Doussis-Anagnostopoulou, K. L. Talks, H. Turley, et al., "Vascular endothelial growth factor (VEGF) is expressed 
by neoplastic Hodgkin-Reed-Sternberg cells in Hodgkin's disease," Journal of Pathology, vol. 197, no. 5, pp. 677-683, 2002.

[128] T. Mainou-Fowler, B. Angus, S. Miller, S. J. Proctor, P. R. A. Taylor, and K. M. Wood, "Micro-vessel density and the expression of vascular endothelial growth factor (VEGF) and platelet-derived endothelial cell growth factor (PdEGF) in classical Hodgkin lymphoma (HL)," Leukemia \& Lymphoma, vol. 47, no. 2, pp. 223-230, 2006.

[129] A. T. Stopeck, J. M. Unger, L. M. Rimsza, et al., "A phase II trial of single agent bevacizumab in patients with relapsed, aggressive non-Hodgkin lymphoma: southwest oncology group study S0108," Leukemia \& Lymphoma, vol. 50, no. 5, pp. 728-735, 2009.

[130] B. Pro, A. Younes, M. Albitar, et al., "Thalidomide for patients with recurrent lymphoma," Cancer, vol. 100, no. 6, pp. 11861189, 2004.

[131] P. H. Wiernik, I. S. Lossos, J. M. Tuscano, et al., "Lenalidomide monotherapy in relapsed or refractory aggressive nonHodgkin's lymphoma," Journal of Clinical Oncology, vol. 26, no. 30, pp. 4952-4957, 2008.

[132] T. E. Witzig, P. H. Wiernik, T. Moore, et al., "Lenalidomide oral monotherapy produces durable responses in relapsed or refractory indolent non-Hodgkin's lymphoma," Journal of Clinical Oncology, vol. 27, no. 32, pp. 5404-5409, 2009.

[133] I. Bruns, F. Fox, P. Reinecke, et al., "Complete remission in a patient with relapsed angioimmunoblastic T-cell lymphoma following treatment with bevacizumab," Leukemia, vol. 19, no. 11, pp. 1993-1995, 2005.

[134] D. Aguiar Bujanda, "Complete response of relapsed angioimmunoblastic T-cell lymphoma following therapy with bevacizumab," Annals of Oncology, vol. 19, no. 2, pp. 396-397, 2008.

[135] K. Ramasamy, Z. Lim, A. Pagliuca, J. R. Salisbury, G. J. Mufti, and S. Devereux, "Successful treatment of refractory angioimmunoblastic T-cell lymphoma with thalidomide and dexamethasone," Haematologica, vol. 91, supplement 8, article ECR44, pp. 117-118, 2006.

[136] A. Dogan, L. S. P. Ngu, S. H. Ng, and P. L. Cervi, "Pathology and clinical features of angioimmunoblastic Tcell lymphoma after successful treatment with thalidomide," Leukemia, vol. 19, no. 5, pp. 873-875, 2005.

[137] C. Strupp, M. Aivado, U. Germing, N. Gattermann, and R. Haas, "Angioimmunoblastic lymphadenopathy (AILD) may respond to thalidomide treatment: two case reports," Leukemia \& Lymphoma, vol. 43, no. 1, pp. 133-137, 2002.

[138] S. M. Horwitz, "Novel therapies for cutaneous T-cell lymphomas," Clinical Lymphoma \& Myeloma, vol. 8, supplement 5, pp. S187-S192, 2008.

[139] K. S. Reiners, A. Gossmann, E. P. von Strandmann, B. Böll, A. Engert, and P. Borchmann, "Effects of the antiVEGF Monoclonal antibody bevacizumab in a preclinical model and in patients with refractory and multiple relapsed hodgkin lymphoma," Journal of Immunotherapy, vol. 32, no. 5, pp. 508-512, 2009.

[140] J. Kuruvilla, K. Song, P. Mollee, et al., "A phase II study of thalidomide and vinblastine for palliative patients with Hodgkin's lymphoma," Hematology, vol. 11, no. 1, pp. 25-29, 2006. 


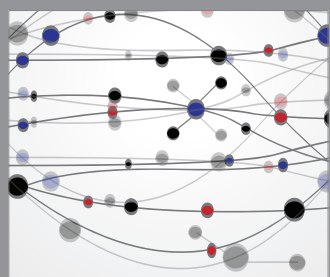

The Scientific World Journal
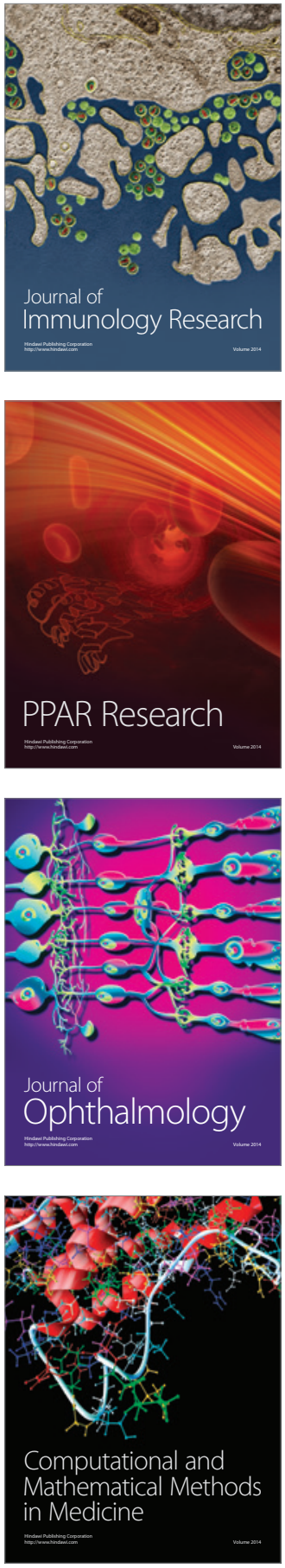

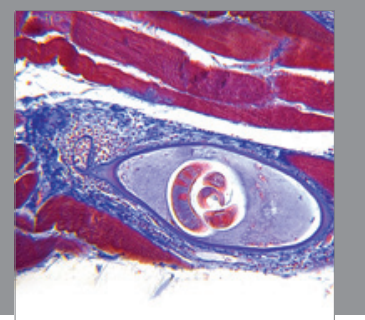

Gastroenterology

Research and Practice
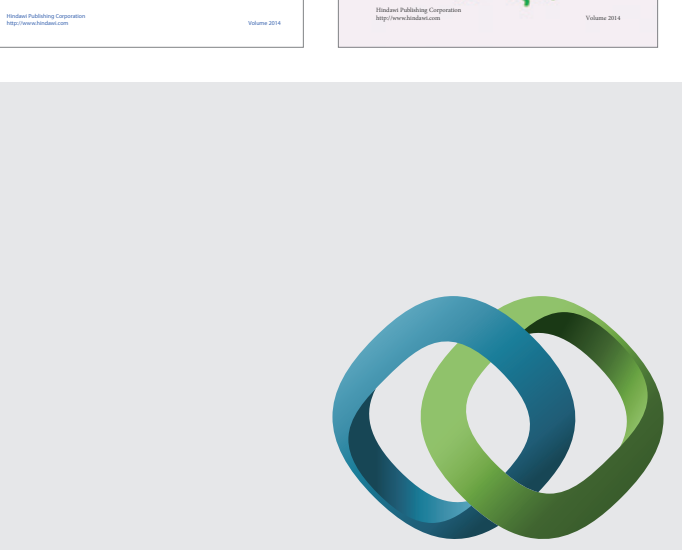

\section{Hindawi}

Submit your manuscripts at

http://www.hindawi.com
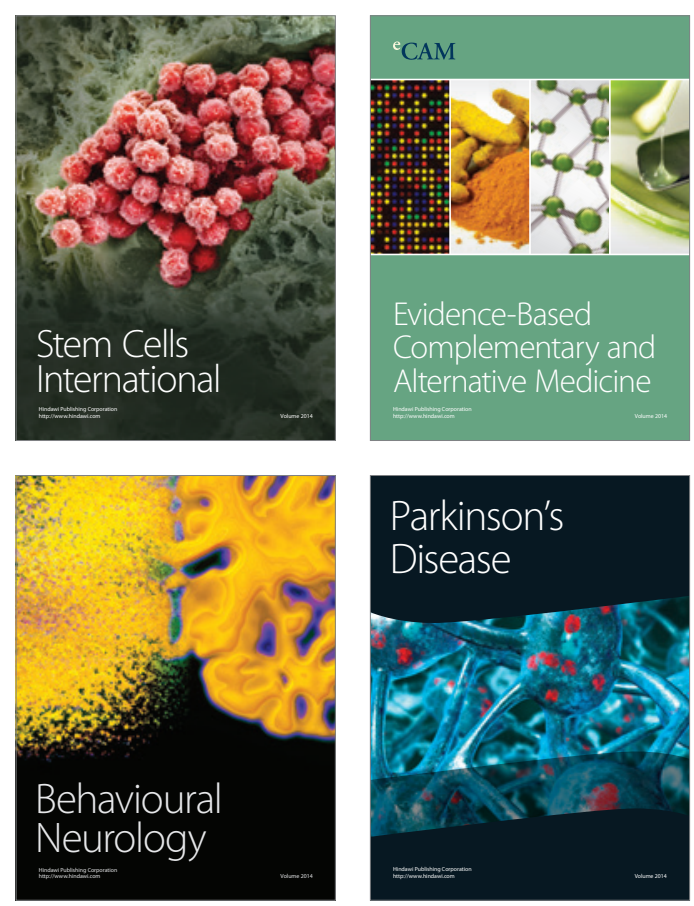

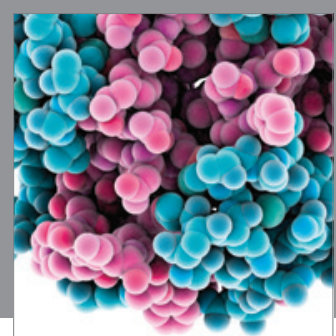

Journal of
Diabetes Research

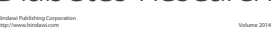

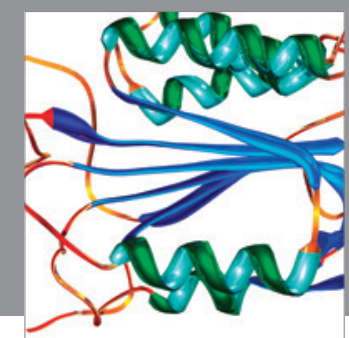

Disease Markers
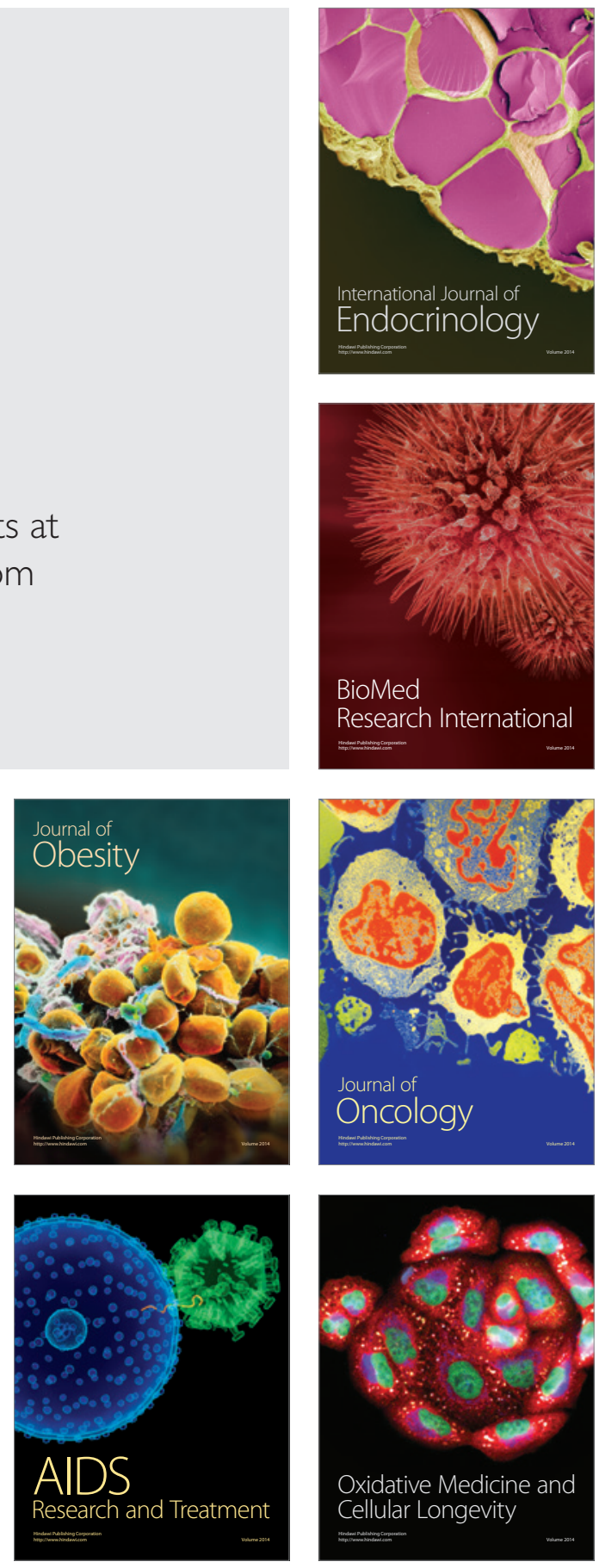